\title{
An analysis of crystal structure of Ca-deficient oxonitridoaluminosilicate, $\mathrm{Ca}_{0.88} \mathrm{Al}_{0.91} \mathrm{Si}_{1.09} \mathrm{~N}_{2.85} \mathrm{O}_{0.15}$
}

\author{
Kyota UHEDA, ${ }^{\dagger}$ Hajime YAMAMOTO, Hisanori YAMANE, ${ }^{*}$ Wataru INAMI, ${ }^{* *}$ Kenji TSUDA, ${ }^{* *}$ \\ Yoshinobu YAMAMOTO*** and Naoto HIROSAKI ${ }^{* * *}$
}

\author{
School of Bionics, Tokyo University of Technology, 1401-1, Katakura-machi, Hachioji 192-0982 \\ *Tohoku University Institute of Multidisciplinary Research for Advanced Materials Center for Advanced Nitride Technology, \\ 2-1-1, Katahira, Aoba-ku, Sendai 980-8577 \\ ***Tohoku University Institute of Multidisciplinary Research for Advanced Materials Center for Advanced Microscopy and \\ Spectroscopy, 2-1-1, Katahira, Aoba-ku, Sendai 980-8577 \\ ${ }^{* * *}$ Nano Ceramics Center, National Institute for Materials Science, 1-1, Namiki, Tsukuba 305-0044
}

A polycrystalline, $\mathrm{Ca}_{0.88} \mathrm{Al}_{0.91} \mathrm{Si}_{1.09} \mathrm{~N}_{2.85} \mathrm{O}_{0.15}$, was synthesized by a solid state reaction in the ternary system $\mathrm{Ca}_{3} \mathrm{~N}_{2}$, AlN, and $\mathrm{Si}_{3} \mathrm{~N}_{4}$, which was accompanied by a two-step heat treatment, $1600^{\circ} \mathrm{C}$ for $2 \mathrm{~h}$ and then $1800^{\circ} \mathrm{C}$ for $2 \mathrm{~h}$ under the nitrogen pres-

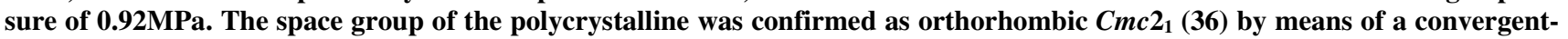
beam electron diffraction (CBED). The lattice parameters were refined using the Rietveld method to be $a=980.005(8), b=$ 564.928(4), and $c=506.241(3) \mathrm{pm}$ with the corresponding weighted profile residual, $R_{\mathrm{wp}}=0.092 . \mathrm{Ca}_{0.88} \mathrm{Al}_{0.91} \mathrm{Si}_{1.09} \mathrm{~N}_{2.85} \mathrm{O}_{0.15}$ was formed due to the creation of cation vacancies at $\mathrm{Ca}^{2+}$ site in $\mathrm{CaAlSiN}_{3}$, which has the isomorphic structure with $\mathrm{LiSi}_{2} \mathrm{~N}_{3}$ and $\mathrm{NaSi}_{2} \mathrm{~N}_{3}$, by partial replacement of $\mathrm{N}^{3-}$ by $\mathrm{O}^{2-}$.

(๑2009 The Ceramic Society of Japan. All rights reserved.

Key-words : Nitride, Oxynitride, Nitridoaluminosilicate, Crystal structure, Crystal system, Convergent-beam electron diffraction (CBED), Red phosphor, LED

[Received September 8, 2008; Accepted November 20, 2008]

\section{Introduction}

Since the 1990s, instead of oxides, which are composed of metal elements and oxygen only, other compounds which consist of the metal elements (especially silicon and/or aluminum), nitrogen and/or oxygen, have been widely studied by developing some new synthetic processes. The compounds are classified into nitrides and oxynitrides, and have attracted attention because they are expected to be a new material by their chemical, physical and thermal stability. Their compounds doped with a transition element with $3 \mathrm{~d}$ or $4 \mathrm{~d}$ electrons, for example, $\mathrm{Ba}_{2} \mathrm{Si}_{5} \mathrm{~N}_{8}: \mathrm{Eu}$, and $\alpha$-sialon, have been intensively studied. ${ }^{1,2)}$ It is because they will be used as a pigment without toxic metals, such as cadmium, lead, and mercury, and as a phosphor, which is coated on a GaN blue emitting chip to fabricate a white LED. We also recently reported that calcium aluminum silicon nitride, $\mathrm{CaAlSiN}_{3}$, doped with europium ions $\left(\mathrm{Eu}^{2+}\right)$ is able to be an excellent phosphor with an intense red luminescence under excitation by blue GaNLEDs. ${ }^{3)}$

$\mathrm{CaAlSiN}_{3}: \mathrm{Eu}^{2+}$ shows a broad excitation spectrum from the ultra violet to the visible region, which suggests the intense red emission is observed by irradiating light with the wide wavelength range. This character is unusual for ordinary phosphor materials, and it is due to the special environment of $\mathrm{Eu}^{2+}$ ion. The environment of $\mathrm{Eu}^{2+}$ ion is coordinated by five nitrogen ions, which are classified according to their bonding with aluminum $\left(\mathrm{Al}^{3+}\right)$, or silicon ion $\left(\mathrm{Si}^{4+}\right)$ in the crystal. Two different environments of $\mathrm{Eu}^{2+}$ ion are formed based on whether or not both $\mathrm{Al}^{3+}$

Corresponding author: K. Uheda; E-mail: ueda.kyouta@mf.mkagaku.co.jp and $\mathrm{Si}^{4+}$ in the crystal are arranged in order. To understand theoretically the unusual character of $\mathrm{Eu}^{2+}$ is possible by studying which environments $\mathrm{Eu}^{2+}$ has in the crystal. $\mathrm{CaAlSiN}_{3}$ has already been reported by Huang et al., ${ }^{4)}$ however, they only indexed it in an orthorhombic unit cell with $a=562.9 \mathrm{pm}, b=$ 958.4pm, and $c=498.6 \mathrm{pm}$. The crystal structure of $\mathrm{CaAlSiN}_{3}$ was not solved in this report.

Recently, Ottinger ${ }^{5)}$ has shown, by the single crystal structure analysis of $\mathrm{CaAlSiN}_{3}$, that the $\mathrm{CaAlSiN}_{3}$ is crystallized in an orthorhombic system with $C m c 2_{1}$ and $a=985.1(5) \mathrm{pm}, b=$ 565.4(3)pm, and $c=507.1(2) \mathrm{pm}$. If $\mathrm{Al}^{3+}$ and $\mathrm{Si}^{4+}$ are arranged in order, the space group, $C m c 2_{1}$, is replaced by a lower space group. However, it is very difficult to determine the ordering or the disordering arrangement of both ions in the crystal structure by the ordinary X-ray diffraction method. It is because there is only a small difference in the atomic scattering factor between $\mathrm{Al}^{3+}$ and $\mathrm{Si}^{4+}$. Although measuring the arrangement of $\mathrm{Al}^{3+}$ and $\mathrm{Si}^{4+}$ in $\mathrm{MgAlSiN}_{3}$ by ${ }^{15} \mathrm{~N}-\mathrm{NMR}$, Harris et al. ${ }^{6)}$ could not obtain a definitive answer as to whether both ions have an ordered structure or a disordered structure.

We have done our own experiments to study the environment of $\mathrm{Eu}^{2+}$ by the crystal structure solution of $\mathrm{CaAlSiN}_{3}$. In this report, we first indexed and analyzed the X-ray diffraction pattern of a sample, which was obtained at temperatures ranging from 1600 to $1800^{\circ} \mathrm{C}$ under $0.92 \mathrm{MPa}$ of $\mathrm{N}_{2}$ pressure. We also confirmed the space group symmetry of $\mathrm{CaAlSiN}_{3}$ by using the CBED technique, which can help to determine its space group, and then discussed two structural models ordering and disordering $\mathrm{Al}^{3+}$ and $\mathrm{Si}^{4+}$ in the crystal. 


\section{Experimental procedure}

$\mathrm{Ca}_{3} \mathrm{~N}_{2}$ (Chemical, Lab., Co., Ltd., 99\%), AlN (Tokuyama Corp., F-grade), $\alpha$ - $\mathrm{Si}_{3} \mathrm{~N}_{4}$ (Ube Ind., Ltd., SN-E10) were weighed to be a molar ratio $\mathrm{Ca}: \mathrm{Al}: \mathrm{Si}=1: 1: 1$, and then mixed in a mortar for $30 \mathrm{~min}$ in a glove box which was filled with pure nitrogen gas. A pellet was prepared by pressing the mixed powder for several minutes, and then placed into a BN crucible. The $\mathrm{BN}$ crucible was moved from the glove box into an electric furnace (Fujidenpa Kogyo Co., Ltd., FVPHP-R-10). After a one-h vacuuming process, the sample was heated at $1600^{\circ} \mathrm{C}$ for $2 \mathrm{~h}$ and then at $1800^{\circ} \mathrm{C}$ for $2 \mathrm{~h}$ under $0.92 \mathrm{MPa}$ of nitrogen. After firing, the obtained sample was crushed into a mortar.

Both the contents of nitrogen and oxygen in the sample powder were estimated by using LECO, TC-436Type. The X-ray diffraction pattern was also measured by RINT2000/PC using $\mathrm{Cu} \mathrm{K} \alpha$ radiation at room temperature. The diffraction peaks were almost completely indexed with the ITO method. ${ }^{7)}$ The unit cell, which is roughly calculated by the ITO method, was further refined by the UNIT CELL program written by Holland et al. ${ }^{8)}$ The model of the crystal structure in a monoclinic system was proposed by EXPO $2000^{9)}$ and then it was refined by RIETAN 2000..$^{10)}$

A sample powder was also suspended in alcohol $\left(\mathrm{C}_{2} \mathrm{H}_{5} \mathrm{OH}\right)$, and then the suspension was deposited onto a copper specimen grid. The specimen was examined in a JEOL transmission electron microscope (TEM) to measure selected areas of electron diffraction (SAED) and CBED patterns.

\section{Results and discussion}

As a result of the amounts of both oxygen and nitrogen contained in the sample after firing under the condition described in the experimental procedure, the atomic ratio of oxygen to the sum of oxygen and nitrogen was estimated to be 0.05 . In the sample, the amount of contaminated oxygen was observed because the starting materials, $\mathrm{Ca}_{3} \mathrm{~N}_{2}, \mathrm{AlN}$, and $\alpha-\mathrm{Si}_{3} \mathrm{~N}_{4}$, had a small amount of oxygen essentially, or the sample had been oxidized during the mixing of those starting materials and the firing process.

A small amount of AlN (less than $1 \%$ mass) was found by phase identification using the X-ray diffraction pattern of the sample. A very weak and broad peak was also observed at around $2 \theta=33.3^{\circ}$, however the peak could not be identified. The other peaks were almost indexed by the ITO method as a hexagonal unit cell. By the linear least squares technique, the lattice parameters in the hexagonal unit cell were refined to be $a=$ $565.45(2)$ and $c=506.40(2) \mathrm{pm}$. A space group is considered to be $P 6_{3}$ (173) or $P 63 / m$ (176) because the peaks of $000 l$ reflections with $l=2 n$ were only observed. In spite of the fact the lattice parameters were precisely given by the refinement, we could not obtain the model of the crystal structure to sufficiently reproduce all of the peaks with various intensities in the hexagonal system using a computer.

The X-ray diffraction pattern could be also indexed as either an orthorhombic C-base centered unit cell or a monoclinic primitive unit cell. If the crystal has the monoclinic lattice, the space group belonged to $P 2_{1}$. We propose two models as follows: $\mathrm{Al}^{3+}$ and $\mathrm{Si}^{3+}$ were each occupied at independent sites in the crystal, and it is named as the "ordering model" (see Fig. 1(a)). The other model, "disordered model," is whereby both ions were located at the same sites statistically (see Fig. 1(b)).

As shown in Fig. 1, the monoclinic $b c$ plane on which Ca ions were arrayed becomes a mirror plane, and then the disordered

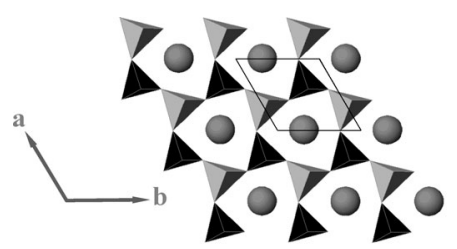

(a)

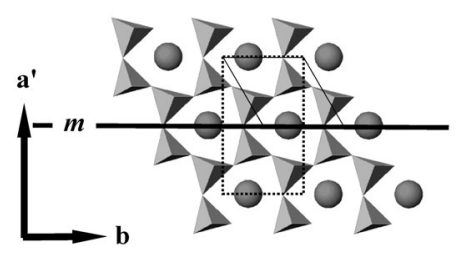

(c)

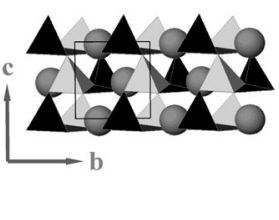

(b)

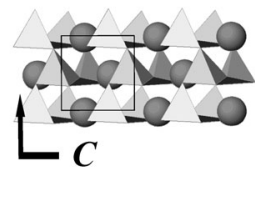

(d)
Fig. 1. Transformation from monoclinic ( $a$ and $b$ ) to orthorhombic (c and d) system for $\mathrm{CaAlSiN}_{3}$. (a) and (c) were described by projecting both unit cells on $a b$ plan, (b) and (d) were also drawn by viewing them along the $a$-axis.

model is transformed to the orthorhombic $C m c 2_{1}$. However, there was very little difference in the weighted profile residual $\left(R_{\mathrm{wp}}\right)$ between the monoclinic and orthorhombic disordered models when the X-ray diffraction pattern was refined in both models using the Rietveld method. Therefore, we could not completely select one of the two alternatives, and tried to observe the electron diffraction of the sample powder to determine the space group.

Figure 2(a) shows SAED pattern of a sample powder at room temperature. CBED patterns with beam aligned along one of unit cell axes were also shown in Figs. 2(b) and (c). Figure 2 (c) represented the whole pattern (WP), while Fig. 2(b), which are called the bright-field pattern (BP), corresponded to that the center of WP was enlarged and further represented by using various grey-levels. As shown in Figs. 2(b) and (c), the symmetry of CBED consisted of a two-fold rotation and two types of mirror symmetry.

The SAED and CBED patterns observed from the direction which was perpendicular to the incidence taken in Fig. 2 were shown in Figs. 3(a), (b), and (c). As shown in Figs. 3(b) and (c), there was only one mirror plane in both patterns. The mirror plane was the alternative observed in Fig. 2, and the mirror plane, which was vertical to the 2-fold rotation axis in Fig. 2. Therefore, the point group of the sample powder was determined to be $\mathrm{mm} 2$ in the orthorhombic system.

After SAED patterns in Figs. 2 and 3 were indexed with the orthorhombic symmetry operation, the extinction condition $h+k$ $=2 n$ was observed. This indicated the lattice type was C. The dark lines which were seen in a vertical direction in the figure, were observed in both 001 and $00 \overline{1}$ diffraction disks in Fig. 3 (b) by the dynamical extinction rule. This indicated that a two-fold screw axis exists in the direction of the $c$-axis. There is only one space group which has the point group of $m m 2$, the lattice type of $\mathrm{C}$, and a two-fold axis, and it was determined that the space group of the sample was $C m c 2_{1}$ (no. 36).

Crystallographic data refined by the Rietveld method as the space group of $C m c 2_{1}$ were summarized in Table 1. Figure 4 also shows the difference between the X-ray diffraction patterns measured from the sample powder and calculated by the RIETAN 2000. As shown in Fig. 4, the crystallographic data were well-refined because there was a small difference between 

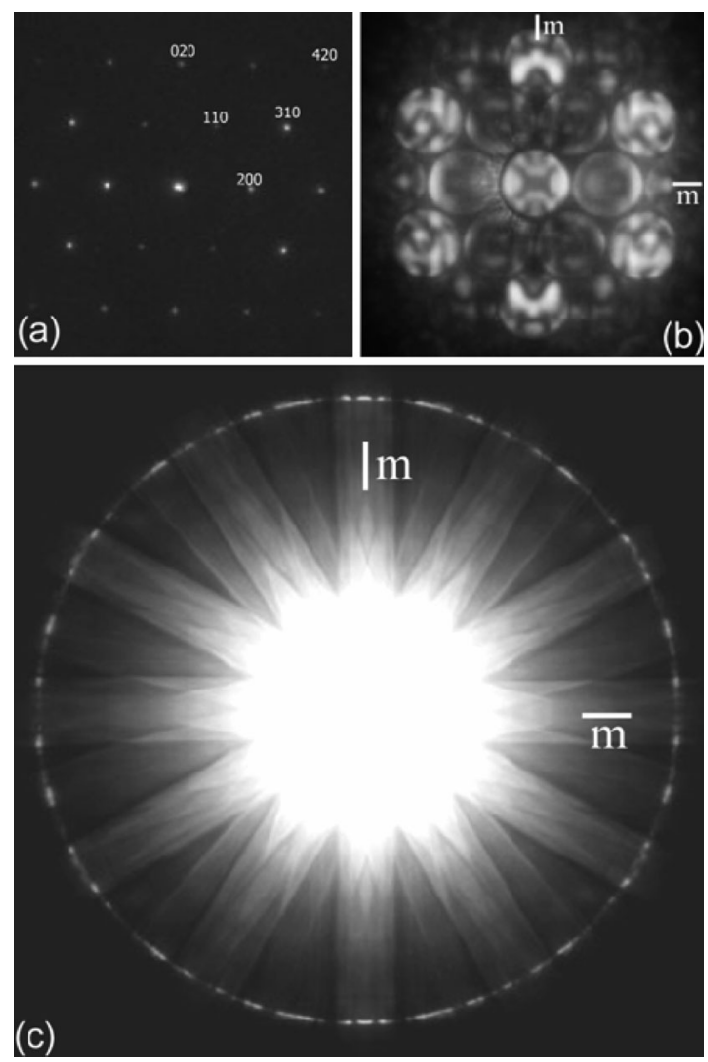

Fig. 2. SAED pattern (a) and the whole CBED pattern (c) of the sample powder at room temperature were taken from the incident along one of the axes in the unit cell at room temperature. The center of the CBED pattern was enlarged in Fig. 2(b).
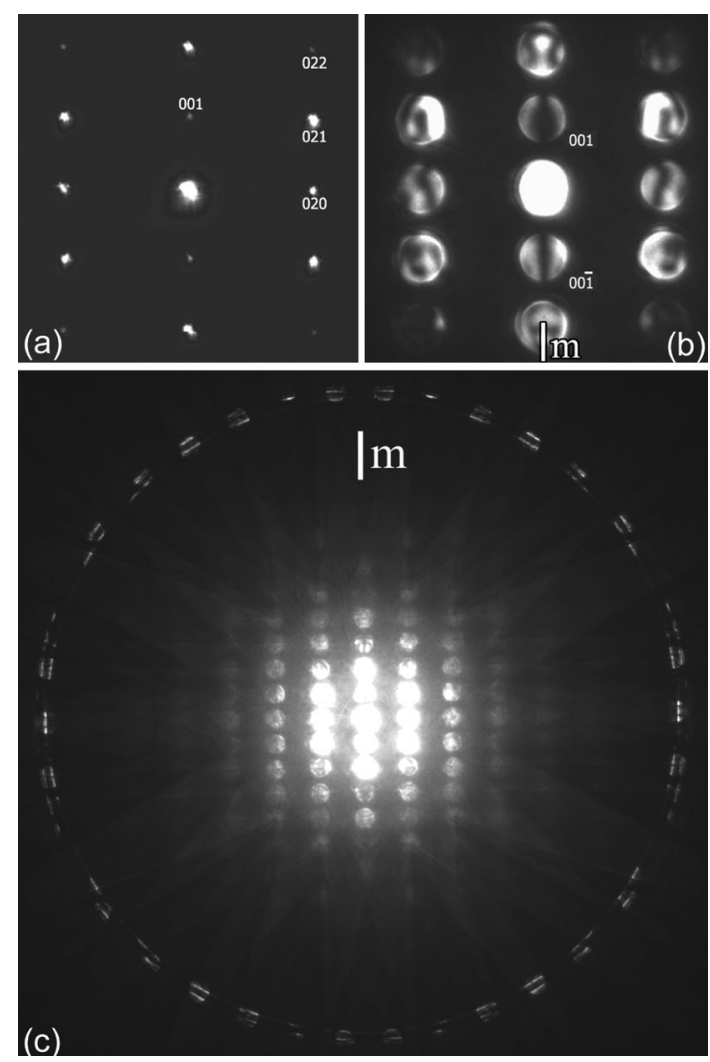

Fig. 3. SAED pattern (a) and the whole CBED pattern (c) at room temperature were taken from the other incident perpendicular to the incident used in Fig. 2 at room temperature. The center of the CBED pattern is enlarged in Fig. 3(b)

Table 1. Crystallographic Data and Structure Refinement for $\mathrm{Ca}_{0.88} \mathrm{Al}_{0.91} \mathrm{Si}_{1.09} \mathrm{~N}_{2.85} \mathrm{O}_{0.15}$

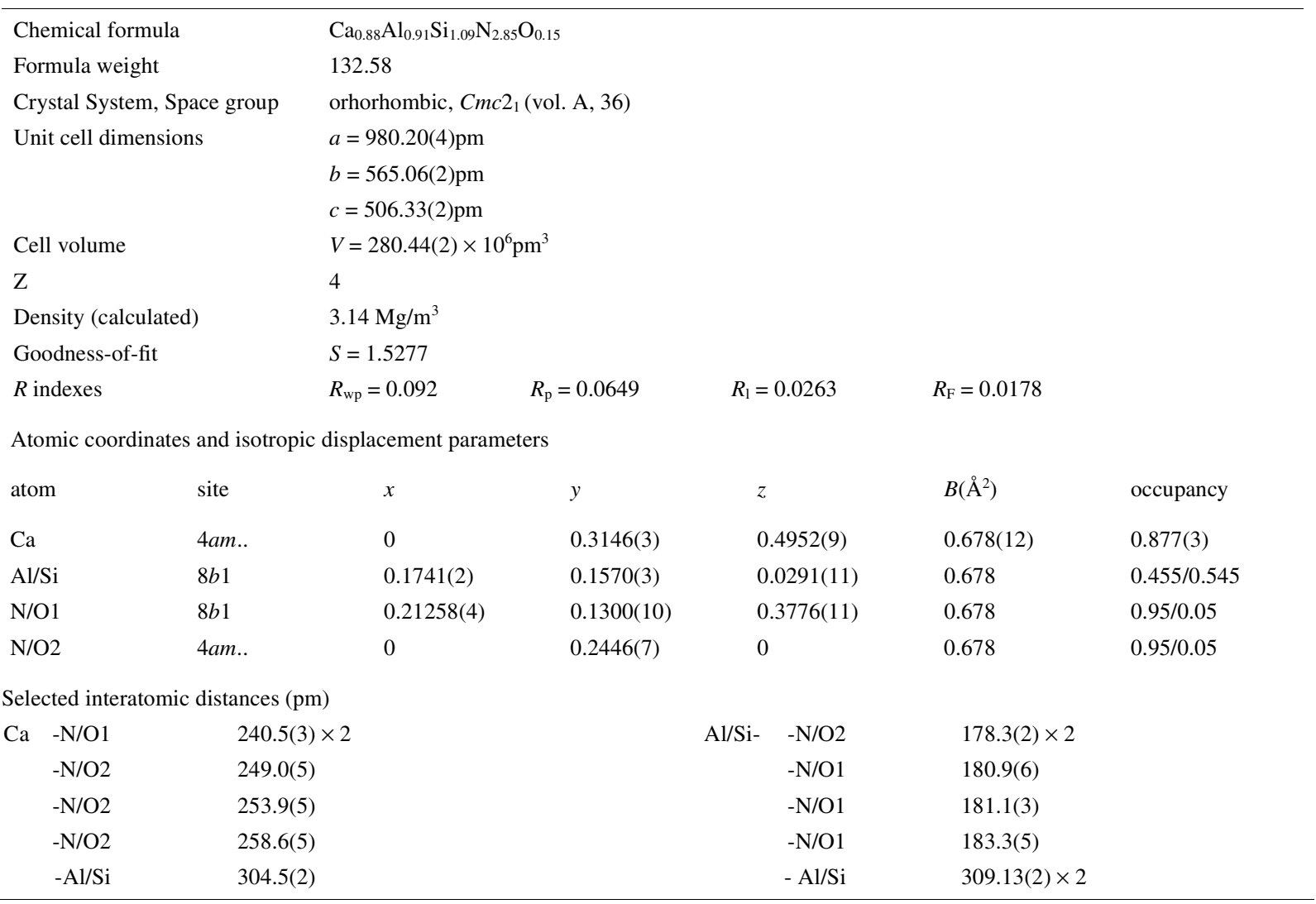




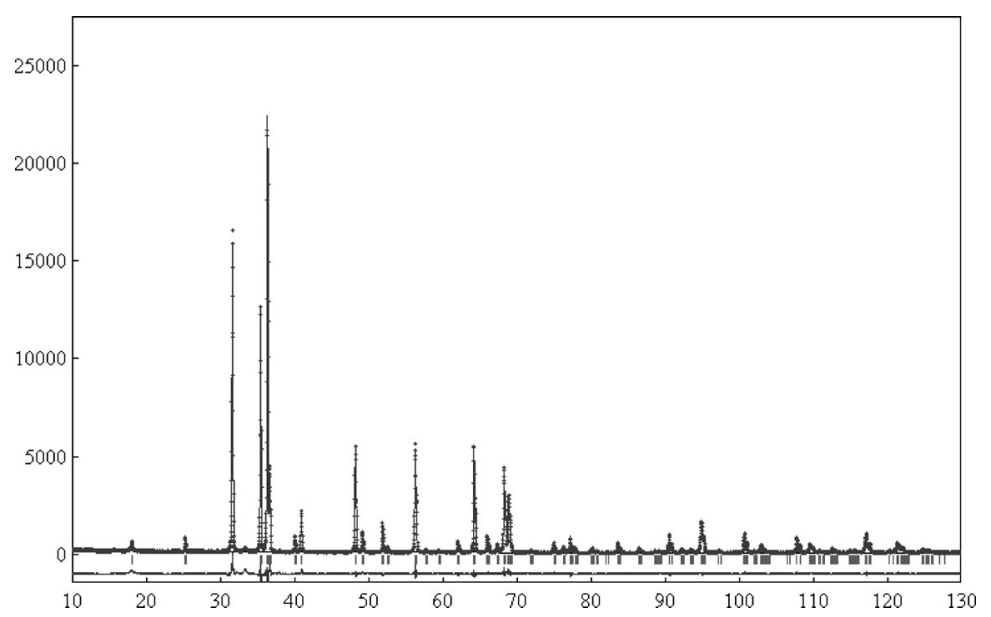

Fig. 4. Observed (dotted line) and calculated (solid line) diffraction patterns of CaAlSiN $\mathrm{C}_{3}$. The difference between the observed and calculated scattered intensity in the range from $10^{\circ}$ to $130^{\circ}$ is shown in the lower part of this figure.

both patterns.

The lattice parameters refined by RIETAN $2000(a=980.20(4)$, $b=565.06(2), c=506.33(2) \mathrm{pm}$ ) was between those reported by Huang et al. ${ }^{4)}$ and Ottinger. ${ }^{5)}$ The parameters were further close to those reported by Ottinger rather than Huang et al. When we first refined the crystal structure of the sample powder as the stoichiometric composition of $\mathrm{CaAlSiN}_{3}$, the isothermal temperature factor of the Ca site in the crystallographic data was estimated to become larger and be 1.15(3). As the temperature factor was much larger than $0.39(2)$ of $\mathrm{Si}$ and $0.10(6)$ of $\mathrm{N}$, the small number of the defects of $\mathrm{Ca}$ ions were considered to be dispersed in the crystal. As a result of the refinement by RIETAN 2000, the sample powder contained less than $1 \%$ mass of AlN as mentioned above. As shown in Fig. 4, the slight increase in the background and small peaks were both observed in the $2 \theta$ angles ranging from $30^{\circ}$ to $35^{\circ}$ in the $\mathrm{X}$-ray diffraction pattern, and it was indicated that a small amount of $\mathrm{Ca}$ was deposited as a glass phase or unknown phase, except for producing $\mathrm{CaAlSiN}_{3}$. The deficiencies of $\mathrm{Al}$ and $\mathrm{Ca}$ in the chemical composition, $\mathrm{Ca}_{0.88} \mathrm{Al}_{0.91} \mathrm{Si}_{1.09} \mathrm{~N}_{2.85} \mathrm{O}_{0.15}$, calculated by RIETAN 2000 were observed in comparison with the mixing ratio of starting materials. It is because unreacted AlN remained and Ca was consumed with formation of the glass or unknown phase in the calcined powder.

The site-occupancy parameter of the $\mathrm{Ca}^{2+}$ ion was refined under the constraint of the fact that isothermal temperature factors of all atomic sites in the unit cell were equaled. As a result, the temperature factor was calculated to be $0.678(12)$ in Table 1 , and it was confirmed that approximately $10 \%$ of the atoms were lacking in the $\mathrm{Ca}$ site. As described previously, $5 \%$ of nitrogen in the anion sites in the crystal was replaced by oxygen. When assuming that the ratio, $5 \%$, was absolutely not changed in each phase, such as the main, third and glass phases, which were contained in the sample powder, the chemical composition of the main phase in the sample powder, "the deficient solid solution of CaAlSiN 3 ," was estimated to be $\mathrm{Ca}_{0.88} \mathrm{Al}_{0.91} \mathrm{Si}_{1.09} \mathrm{~N}_{2.85} \mathrm{O}_{0.15}$.

Jacobs and Mengis ${ }^{11)}$ have reported that $\mathrm{NaSi}_{2} \mathrm{~N}_{3}$, which can be represented as $1 / 3\left[\left(\mathrm{NaSi}_{2}\right) \mathrm{N}_{3}\right]$, is homeotypic with $\mathrm{ZnO}$ (zincite) or $\mathrm{ZnS}$ (wurzite). $\mathrm{CaAlSiN}_{3}$, which has a similar structure with $\mathrm{NaSi}_{2} \mathrm{~N}_{3}$, is also homeotypic of $\mathrm{ZnO}$ or $\mathrm{ZnS}$. Space group; $C m c 2_{1}$ belonged to $\mathrm{Pb}_{3} m c$, which is a maximal non-isomorphic sub-

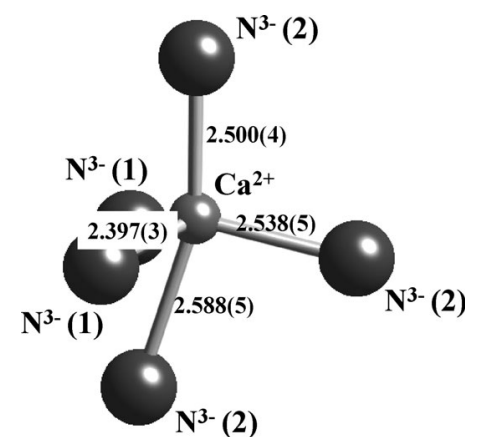

Fig. 5. Coordination geometry around calcium in $\mathrm{CaAlSiN}_{3}$.

group of $\mathrm{ZnO}$. In the wurzite structure, all of the cations and anions are piled up in a hexagonal close-packed arrangement. Both ions in the structure were occupied in the half of the tetrahedral sites in which a cation or anion was coordinated by the four anions. In $\mathrm{CaAlSiN}_{3}, \mathrm{Al}$ or $\mathrm{Si}$ was randomly occupied at $\mathrm{Al} / \mathrm{Si}$ sites. Each $\mathrm{Al} / \mathrm{Si}$ site was also tetrahedral, coordinated by four nitrogens in N/O site, which contained 5\% oxygen. The mean bond length of $\mathrm{Al} / \mathrm{Si}-\mathrm{N}$ was calculated to be $179.7 \mathrm{pm}$.

As shown in Fig. 1, the larger $\mathrm{Ca}$ ion was pushed into the N/O plane composed of nitrogen and oxygen, by moving their anions aside. The bond length between $\mathrm{Ca}^{2+}$ and an anion in N/O2 site was estimated to be 268.6(5)pm. According to Reckweg and DiSalvo, ${ }^{12)}$ the coordination number of $\mathrm{Ca}$ in $\mathrm{Ca}_{3} \mathrm{~N}_{2}$ (cubic antibixbyte structure, $I a-3)$ is four, and the bond length between $\mathrm{Ca}$ and $\mathrm{N}$ was from 245.1(2) to 248.3(1). Ca ion in $\mathrm{CaMg}_{2} \mathrm{~N}_{2}$ (antiC- $\mathrm{M}_{2} \mathrm{O}_{3}$ structure, $P-3 m 1$ ) has also the coordination number of 6 , and the mean bond length of $\mathrm{Ca}-\mathrm{N}$ was 259.5(2)pm. As shown in Fig. 5, Ca ion in $\mathrm{Ca}_{0.88} \mathrm{Al}_{0.91} \mathrm{Si}_{1.09} \mathrm{~N}_{2.85} \mathrm{O}_{0.15}$ was coordinated by five N/O anions, and the bond lengths between $\mathrm{Ca}$ and N/O were estimated to be from 240.5(3) to $258.6(5) \mathrm{pm}$. The bond lengths were close to those in the case that $\mathrm{Ca}$ ion has a coordination number of four or six.

The framework of $\mathrm{CaAlSiN}_{3}$, in which $\mathrm{Al}$ and $\mathrm{Si}$ was disordered, has the same structure of $\mathrm{Si}_{2} \mathrm{~N}_{2} \mathrm{O} .{ }^{13)} \mathrm{Si}_{2} \mathrm{~N}_{2} \mathrm{O}$ can be described as $(\square, \mathrm{Si})_{3}(\mathrm{~N}, \mathrm{O})_{3}$, and the crystal structure is that $1 / 3$ of the cation site is lacked in wurtizte. The site of $\mathrm{Ca}$ ion was 
surrounded by six tetrahedra in which $\mathrm{Al} / \mathrm{Si}$ was coordinated by four nitrogens in a layer perpendicular to the $c$-axis. The twodimensional sheets paralled to $a b$ plane were formed by a corner sharing $\mathrm{Al} / \mathrm{Si}-(\mathrm{N}, \mathrm{O})_{4}$ tetrahedra of each other. (unsure if this is what author is trying to convey) Keeping the symmetry of $2_{1}$ screw axis, these sheets were stacked along the $c$-axis to build up a three dimensional structure

$\mathrm{Ca}_{0.88} \mathrm{Al}_{0.91} \mathrm{Si}_{1.09} \mathrm{~N}_{2.85} \mathrm{O}_{0.15}$ is considered to be a solid solution by mixing $\mathrm{CaAlSiN}_{3}$ and $\mathrm{Si}_{2} \mathrm{~N}_{2} \mathrm{O}$. In the report by Huang et al., ${ }^{4)}$ $\mathrm{CaAlSiN}_{3}$ and AlN existed in a wider range in the system, $3 \mathrm{CaO} \cdot \mathrm{Si}_{2} \mathrm{~N}_{2} \mathrm{O}-2 \mathrm{CaO} \cdot \mathrm{Si}_{3} \mathrm{~N}_{4}-\mathrm{AlN}$, above $1500 \mathrm{C}$, and the lattice parameters were different from those reported by Ottinger and calculated in this report. Therefore, there are expected to be a wide variety of solid-solutions with defects between $\mathrm{CaAlSiN}_{3}$ and $\mathrm{Si}_{2} \mathrm{~N}_{2} \mathrm{O}$.

\section{Conclusion}

A polycrystalline, $\mathrm{Ca}_{0.88} \mathrm{Al}_{0.91} \mathrm{Si}_{1.09} \mathrm{~N}_{2.85} \mathrm{O}_{0.15}$, was synthesized by a solid state reaction in the ternary system $\mathrm{Ca}_{3} \mathrm{~N}_{2}, \mathrm{AlN}$, and $\mathrm{Si}_{3} \mathrm{~N}_{4}$. By measuring CBED, the crystalline was confirmed to belong to the space group symmetry, $C m c 2_{1}$ and then the crystallographic parameters were refined by the Rietveld method again. As a result, it is suggested obviously that $\mathrm{Al}^{3+}$ and $\mathrm{Si}^{4+}$ occupied randomly at same site in the crystal structure, and $\mathrm{Ca}_{0.88} \mathrm{Al}_{0.91} \mathrm{Si}_{1.09} \mathrm{~N}_{2.85} \mathrm{O}_{0.15}$ was clearly produced from CaAlSiN $\mathrm{C}_{3}$ with cation vacancies.

Acknowledgements This research was sponsored by the Scientific Research of Priority Areas Research Programs "Panoscopic
Assembling and High Ordered Functions for Rare Earth Materials," of Ministry of Education, Culture, Sports, Science and Technology of Japan.

\section{References}

1) J. W. H. van Krevel, J. W. T. van Rutten, H. Mandal, H. T. Hintzen and R. Metselaar, J. Solid State Chem., 165, 19-24 (2002).

2) R.-J. Xie, M. Mitomo, K. Uheda, F.-F. Xu and Y. Akimune, J. Am. Ceram. Soc., 85, 1229-1234 (2002).

3) K. Uheda, N. Hirosaki and H. Yamamoto, Phys. Stat. Sol. (a), 203, 2712-2717 (2006).

4) Z.-K. Huang, W.-Y. Sun and D.-S. Yan, J. Mater. Sci, Lett., 4, 255-259 (1985).

5) F. Ottinger, Ph. D. Thesis, Universität Karlsruhe, 2004, 112.

6) R. K. Harris, M. J. Leach and D. P. Tompson, Chem. Mater., 4, 260-267 (1992).

7) T. Ito, Nature, 164, 755-756 (1949).

8) T. J. B. Holland and S. A. T. Redfern, Mineralogical Magazine, 61, 65-77 (1997).

9) A. Altomare, M. C. Burla, M. Camalli, B. Carrozzini, G. L. Cascarano, C. Giacovazzo, A. Guagliardi, A. G. G. Moliterni, G. Polidori and R. Rizzi, J. Appl. Cryst., 32, 339-340 (1999).

10) F. Izumi and T. Ikeda, Mater. Sci. Forum, 321-324, 198-203 (2000).

11) H. Jacobs and H. Mengis, Eur. J. Solid State Inorg. Chem., 30, 45-53 (1993).

12) O. Reckeweg and F. J. DiSalvo, Z. Anorg. Allg. Chem., 627, 371-377 (2001).

13) W. H. Baur and T. J. McLarnan, J. Solid State Chem., 42, 300321 (1982). 